\title{
Effectiveness of a law to reduce alcohol-impaired driving in Japan
}

\author{
T Nagata, ${ }^{1,2}$ S Setoguchi, ${ }^{3}$ D Hemenway, ${ }^{4}$ M J Perry ${ }^{5}$
}

${ }^{1}$ Takemi Program, Department of International Health, Harvard School of Public Health, Boston, MA, USA; ${ }^{2}$ Department of Emergency Medicine, St Mary's Hospital, Kurume, Japan;

${ }^{3}$ Division of

Pharmacoepidemiology and Pharmacoeconomics, Brigham and Women's Hospital, Boston, MA, USA; ${ }^{4}$ Department of Health Policy and Management, Harvard School of Public Health, Boston, MA, USA; ${ }^{5}$ Department of Environmental Health, Harvard School of Public Health, Boston, MA, USA

Correspondence to:

Dr T Nagata, Department of Emergency Medicine, St Mary's Hospital, 422 Tsubukuhonmachi, Kurume-city, 830-0047, Japan: nagata.takashi@gmail.com

Accepted 29 November 2007

\section{ABSTRACT}

Objective: To estimate the effect of a new road traffic law against alcohol-impaired driving in Japan.

Methods: Japan passed a new road traffic law in June 2002 intended to reduce alcohol-impaired driving by decreasing the permissible blood alcohol level and by increasing penalties. Using data collected from police reports, the number of traffic fatalities and injuries were analyzed by time series.

Results: Simple comparisons of the average of all severe traffic injuries, traffic fatalities, alcohol-impaired traffic injuries, alcohol-impaired severe traffic injuries, and alcohol-impaired traffic fatalities per billion kilometers driven showed reductions after enactment of the new road traffic law in June 2002. The rate of alcohol-related traffic fatalities per billion kilometers driven decreased by $38 \%$ in the post-law period. In segmented regression analyses with adjustment for baseline trends, seasonality, and autocorrelation, all traffic injuries, severe traffic injuries, alcohol-impaired traffic injuries, alcohol-impaired severe traffic injuries, and alcohol-impaired traffic fatalities per billion kilometers driven declined significantly from baseline after the new traffic law.

Conclusion: Large, immediate public health benefits resulted from the new road traffic law in Japan.

Traffic injury is a worldwide public health issue. Annually, more than a million people are killed on the world's roads; in the USA there are over 40000 motor vehicle fatalities each year. ${ }^{1}$ In April 2004, The World Health Organization (WHO) and World Bank released the World report on road traffic injury prevention. ${ }^{2}$ It stated that, in 1990, road traffic injuries were the ninth leading contributor to the global burden of disease, but are predicted to become the third leading contributor by 2020 , unless appropriate action is taken.

Alcohol-impaired driving (AID) is a leading cause of traffic fatality both in developed and developing countries. A review of studies in low- and middleincome countries found that blood alcohol was detected in 33-66\% of fatally injured drivers. ${ }^{2}$ Although drinking and driving legislation, including administrative license suspension, random screening, and lowering the legal blood alcohol limit, has been shown to reduce traffic fatalities, many countries have not enacted such measures.

In Japan, the absolute number of traffic deaths fell from 11451 in 1992 to 7358 in 2004, an average decrease of $3-4 \%$ per year. The National Police Agency (NPA) states that this reduction is due to improvements in policy, roads, vehicle engineering, driver behavior, and the nation's emergency medical system. ${ }^{4}$
In the 1990s, blood alcohol was detected in 14 $16 \%$ of fatally injured drivers in Japan. ${ }^{5}$ To reduce alcohol-related traffic fatalities, in June 2002, the Japanese government enacted a new road traffic law against AID. The law reduced the allowable breath alcohol test from 0.25 to $0.15 \mathrm{mg} / \mathrm{l}$ and blood alcohol concentration (BAC) from $0.05 \%$ to $0.03 \%$, and increased the penalties for AID. The fine increased from approximately 50000 to 500000 Yen (US\$425 to $\$ 4250$ in 2002), and driver's license points were severely imposed. Moreover the law made bartenders and passengers culpable in addition to arrested drivers. ${ }^{45}$

This study evaluates the impact of this new law on traffic injuries and fatalities in Japan using time series analysis. We test the null hypothesis that the new road traffic law did not reduce AID traffic fatalities, AID severe traffic injuries, or AID traffic injuries; nor did it reduce traffic fatalities, severe traffic injuries, or all traffic injuries. The alternative hypothesis is that there were significant changes in the time series intercept or slope after enactment of the law.

\section{METHODS}

\section{Data and their source}

Two data sources were used, the NPA Crash Reports and the Ministry of Land Infrastructure and Transport Driving Data. The NPA Crash Reports are managed by the traffic bureau of the NPA. ${ }^{4}$ Data on traffic crashes are reported by local police stations and then centralized by the NPA. The local police stations use a standardized protocol for data collection, and all data on injuries and deaths are supplied by emergency medical care professionals through medical certificates. Initially all the traffic incidents are collected in the local police stations, then are collected in the headquarters of the prefecture police agencies, and finally systematically reported to the NPA However, the number of traffic injuries in the NPA Crash Reports is thought to be underestimated. ${ }^{6}$ Data on traffic crashes were provided anonymously through the website of the NPA in December 2005. We collected monthly data on the total number of traffic fatalities, severe traffic injuries, and all traffic injuries as well as the total number of AID traffic fatalities, AID severe traffic injuries, and all AID traffic injuries from January 1998 to December 2004. ${ }^{4}$

The Ministry of Land Infrastructure and Transport provides public monthly and annual data on total kilometers driven in Japan. Total kilometers driven is defined as the total distance driven by all of the registered vehicles in Japan. Total kilometers driven are measured on the basis unlocked.dt 
Table 1 Incidence of traffic injuries in Japan (2004)

\begin{tabular}{lrcc}
\hline & \multicolumn{1}{c}{ Total } & $\begin{array}{c}\text { Per } \mathbf{1 0 0} \mathbf{0 0 0} \\
\text { population }\end{array}$ & $\begin{array}{c}\text { Per billion } \\
\text { km driven }\end{array}$ \\
\hline All traffic injuries & 1190487 & 932.3 & 1239.6 \\
All severe traffic injuries & 72777 & 57.0 & 75.8 \\
All traffic fatalities & 7358 & 5.8 & 7.7 \\
AID traffic injuries & 22291 & 17.5 & 23.2 \\
AID severe traffic injuries & 2081 & 1.6 & 2.2 \\
AID traffic fatalities & 761 & 0.6 & 0.8 \\
Total population & 127687000 & - & - \\
Total km driven & 960384603 & - & - \\
\hline
\end{tabular}

AID, alcohol-impaired driving.

of specifications by the census law. About 30000 samples among 77000000 registered vehicles in Japan are chosen randomly and anonymously. Monthly total kilometers driven by each vehicle is exactly measured according to the odometer readings. We obtained the monthly data on total kilometers driven from January 1998 to December 2004 from the website of the Ministry of Land Infrastructure and Transport. ${ }^{8}$

The study used data available in the public domain, and was given human subjects exemption by the Harvard School of Public Health Human Subjects Committee.

\section{Traffic injuries, traffic fatalities, and rates}

In Japan, the sample of traffic injuries in motor vehicle incidents includes those of drivers and passengers, and $78 \%$ of traffic fatalities and $82 \%$ of all traffic injuries occur to drivers in the official police report. ${ }^{4}$ Traffic fatalities are defined as deaths within $24 \mathrm{~h}$ of a crash on a road involving a vehicle with an engine, the death being the result of the crash. Thus, fatality data include all motor vehicle-related deaths (eg, trucks, motorcars, motorcycles, bicycles, pedestrians). Severe traffic injuries are defined as injuries that resulted in more than 30 days of medical care after the incident, which includes both hospitalization and outpatient treatment. All traffic injuries are defined as any traffic injuries reported to the NPA, which include severe traffic injuries and fatalities. AID traffic fatalities, severe traffic injuries, and total traffic injuries are counted as the number of incident cases involving AID. Involvement of AID is determined by the police using breath tests. Before June 2002, AID was defined as a measurement of alcohol $>0.25 \mathrm{mg} / \mathrm{l}$ by a breath test or $>0.05 \%$ by blood alcohol test. After June 2002, AID was defined as $>0.15 \mathrm{mg} / \mathrm{l}$ by a breath test or $>0.03 \%$ by blood alcohol test. The number of AID cases was divided by total kilometers driven to calculate the rates for traffic fatalities, severe traffic injuries, and all traffic injuries.

In this study, we calculated rates using total number of traffic fatalities, severe traffic injuries, all traffic injuries, in addition to AID traffic fatalities, AID severe traffic injuries, and AID traffic injuries divided by total kilometers driven.

\section{Statistical analysis}

First, simple counts were made of the annual nationwide traffic fatalities from January 1998 to May 2002 (pre-law) compared with June 2002 to December 2004 (post-law). We next conducted segmented regression analyses to evaluate the effectiveness of the June 2002 traffic law on AID after adjustment for pre-intervention trends and for seasonality of traffic injuries. ${ }^{9}$ Because of the large number of observations, we assumed normal distributions of monthly rates and conducted least squares linear regression. We tested for first- and higherorder autocorrelation by calculating ordinal and generalized
Table 2 Average national traffic fatalities, severe traffic injuries and traffic injuries per billion kilometers driven before and after enactment of the new road traffic law, Japan (January 1998-May 2002 compared with June 2002-December 2004)

\begin{tabular}{lrrc}
\hline & Pre-law & Post-law & $\begin{array}{l}\text { Percentage } \\
\text { change }\end{array}$ \\
\hline All traffic injuries & 1156.57 & 1229.02 & +6.1 \\
All severe traffic injuries & 80.76 & 77.71 & -3.8 \\
All traffic fatalities & 9.34 & 8.00 & -14.3 \\
AID traffic injuries & 36.74 & 24.77 & -32.6 \\
AID severe traffic injuries & 3.68 & 2.33 & -36.7 \\
AID traffic fatalities & 1.39 & 0.86 & -38.1 \\
\hline
\end{tabular}

AID, alcohol-impaired driving.

Durbin-Watson statistics. ${ }^{10}$ When autocorrelation was detected, we used stepwise autoregression to select the order of the autoregressive error models. ${ }^{11}$ Calendar month served as the unit of analysis, with the primary outcome measure being the event rate. Six events (monthly rate of traffic fatalities, severe traffic injuries, all traffic injuries, in addition to alcoholrelated traffic fatalities, severe traffic injuries, all traffic injuries) were modeled. There were 84 monthly intervals: 53 before the intervention, and 31 after the intervention. The formula for the basic model is as follows:

$Y_{t}=\beta_{0}+\beta_{1^{*}}$ Time $_{t}+\beta_{2^{*}}$ Intervention ${ }_{t}+\beta_{3^{*}}$ Time after Intervention ${ }_{\mathrm{t}}+\beta_{4^{*}}$ February $+\beta_{5^{*}}$ March $+\beta_{6^{*}}$ April $+\beta_{7^{*}}$ May + $\beta_{8^{*}}$ June $+\beta_{9^{*}}$ July $+\beta_{10^{*}}$ August $+\beta_{11^{*}}$ September $+\beta_{12^{*}}$ October $+\beta_{13^{*}}$ November $+\beta_{14^{*}}$ December $+V_{i}$

where: $Y_{t}$ is a monthly rate of traffic fatalities, severe injuries, and total injuries per vehicle kilometer driven per month; $b_{i}$ represent the coefficients of the model $t$; Time is a continuous variable indicating the time in months at time $t$ from the start of the observation period (in this study it started in January 1998 through December 2004); Intervention is an indicator for time $\mathrm{t}$ occurring before (intervention $=0$ ) or after (intervention $=1$ ) the new law, implemented at month 54 (June, 2002) in the series; Time after Intervention is a continuous variable counting the number of months after the intervention at time $t$, coded 0 before the new traffic law and (time-53) after the new traffic law; and $V_{i}$ is autoregressive errors. All analyses were conducted using SAS (SAS Institute, Cary, North Carolina, USA).

A change in either the level or the slope of the time trend beginning at the intervention date suggests an effect of the law.

\section{RESULTS}

In Japan in 2004, there were 7358 traffic fatalities within $24 \mathrm{~h}$ of a crash, 5.8 per 100000 persons (table 1). Traffic injuries totaled 1190487 or 932 per 100000 persons. Severe injuries, totaled 72777 , or 57 per 100000 persons. The proportion of traffic fatalities to severe traffic injuries to total traffic injuries was 1:9.9:162. Just over $10 \%$ of all traffic fatalities were alcoholrelated, under $3 \%$ of all serious traffic injuries were alcoholrelated, and $1.9 \%$ of all injuries were alcohol-related.

Table 2 compares the average annual injuries rates per billion kilometers between January 1998 and May 2002 (pre-law) with the average rates between June 2002 and December 2004 (postlaw). AID traffic fatalities fell by $38 \%$, and AID traffic injuries fell by $33 \%$; all traffic fatalities fell by $14 \%$. For severe traffic injuries, AID traffic injuries, AID severe traffic injuries, and AID traffic fatalities per billion kilometers driven, there were reductions after the new traffic law was enacted in June 2002. 
Figure 1 Observed and predicted (per billion kilometers driven) using a stepwise autoregression model, Japan, 1998-2004. alcohol-impaired driving traffic fatalities

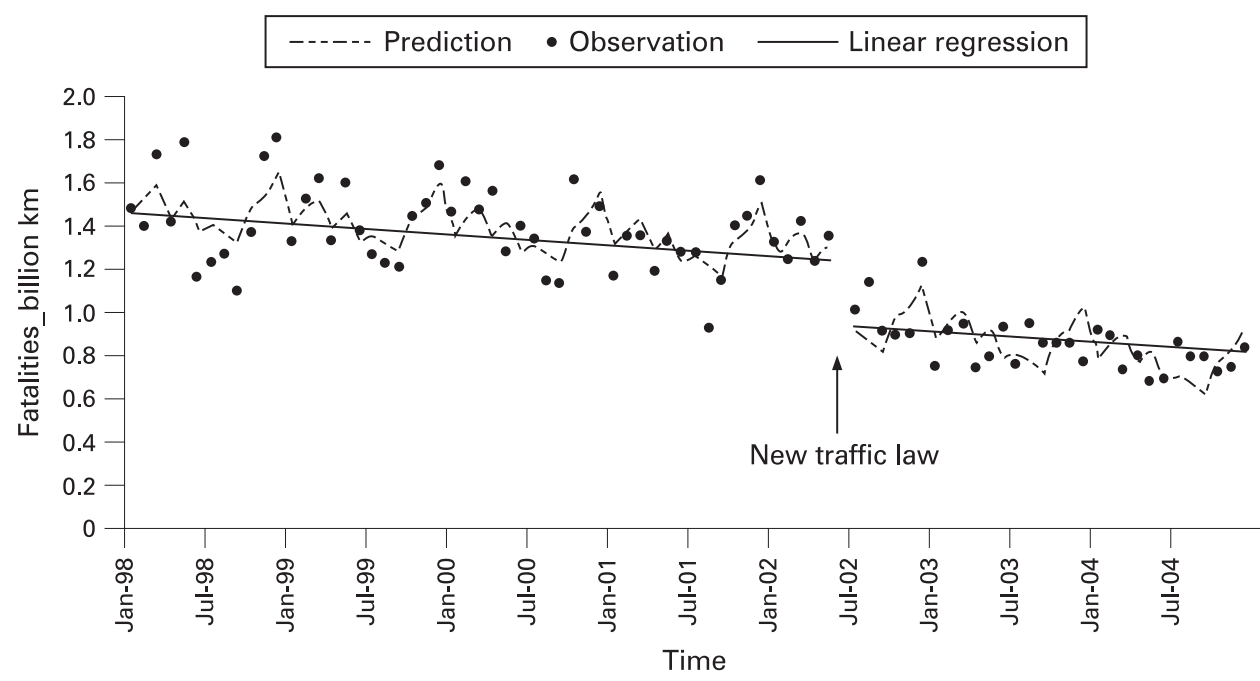

There was no evidence of a reduction for all traffic injuries $(+6 \%)$ during the same periods.

In segmented regression analyses with adjustment for baseline trends, seasonality, and autocorrelation, we found a significant change in the level of AID traffic fatalities (fig 1), AID severe injuries (not shown), and all AID traffic injuries per billion kilometers driven (fig 2). The baseline rate was significantly $(p<0.01)$ reduced by $20 \%, 23 \%$ and $32 \%$ for AID traffic fatalities, severe traffic injuries and all traffic injuries, respectively.

We found no significant change in the slope for time trend before and after the intervention for AID traffic fatalities $(p=0.14) \quad$ (fig 1$)$ and severe traffic injury $(p=0.07)$ (not shown). However, we observed a qualitative change in the slope $(0.1$ to -0.2$)$ for total AID injuries $(p<0.01)$ (fig 2).

For all traffic fatality rates, we observed a $4 \%$ reduction in the baseline rates $(p=0.06)$, but the change in the slope $(-0.024$ to -0.017 ) was not significant $(p=0.51)$ (fig 3$)$. We found $4 \%$ reductions in the baseline rates for both severe traffic injuries $(p=0.05)$ (not shown) and all traffic injuries $(p<0.01)$ (fig 4$)$. The slope in the trend changed from 0.06 to -0.16 for severe traffic injuries $(p<0.01)$ and from 3.89 to 1.64 for all traffic injuries $(p<0.01)$.

Figure 2 Observed and predicted alcohol-impaired driving traffic injuries (per billion kilometers driven) using a stepwise autoregression model, Japan, 1998-2004.

\section{DISCUSSION}

Following the 2002 new road traffic law, which increased the penalties for AID, Japan experienced a significant and substantial reduction in AID traffic problems: fatalities, severe injuries, and all injuries. These results were consistent across all traffic injuries (alcohol-related plus non-alcohol-related), severe traffic injuries, and also total traffic fatalities $(p=0.06)$. In Japan, AID traffic fatalities had been decreasing since the early 1990s, and it appears that the law had an effect over and above this trend. Hitosugi et $a l^{12}$ and Imai $^{13}$ reported a decrease in traffic fatalities after the new law, but did not measure the effect against the already declining traffic fatalities since 1993 in Japan, nor were trends standardized by kilometers driven. This study used time series analysis to demonstrate the effect of the new traffic law, accounting for both the trend and driving exposure. ${ }^{14-16}$

Alcohol remains a major contributor to traffic death throughout the world, although much progress has been made. License suspension, illegal and administrative laws per se, selective and regular enforcement patrols, and sobriety checkpoints have been effective in reducing the harm caused by AID. ${ }^{217}$ The introduction of a legal BAC limit has been effective in the UK, Canada, The Netherlands, and Japan. ${ }^{2}$ In the USA,

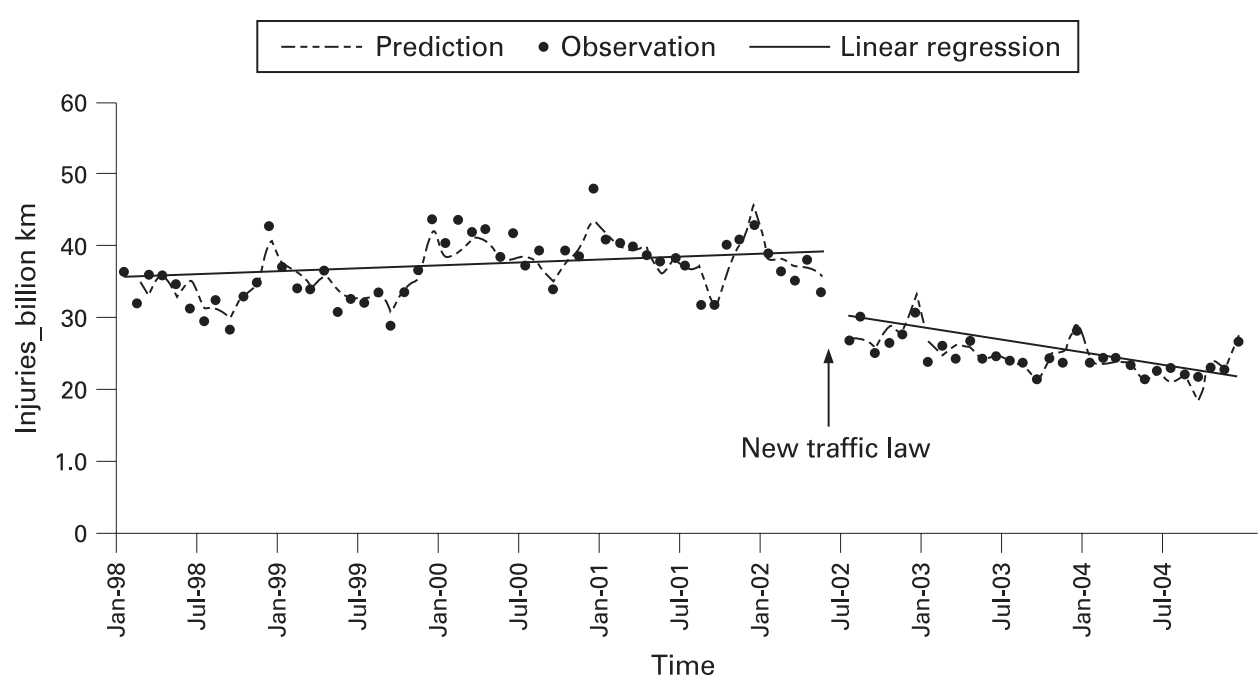


Figure 3 Observed and predicted all traffic fatalities (per billion kilometers driven) using a stepwise autoregression model, Japan, 1998-2004.

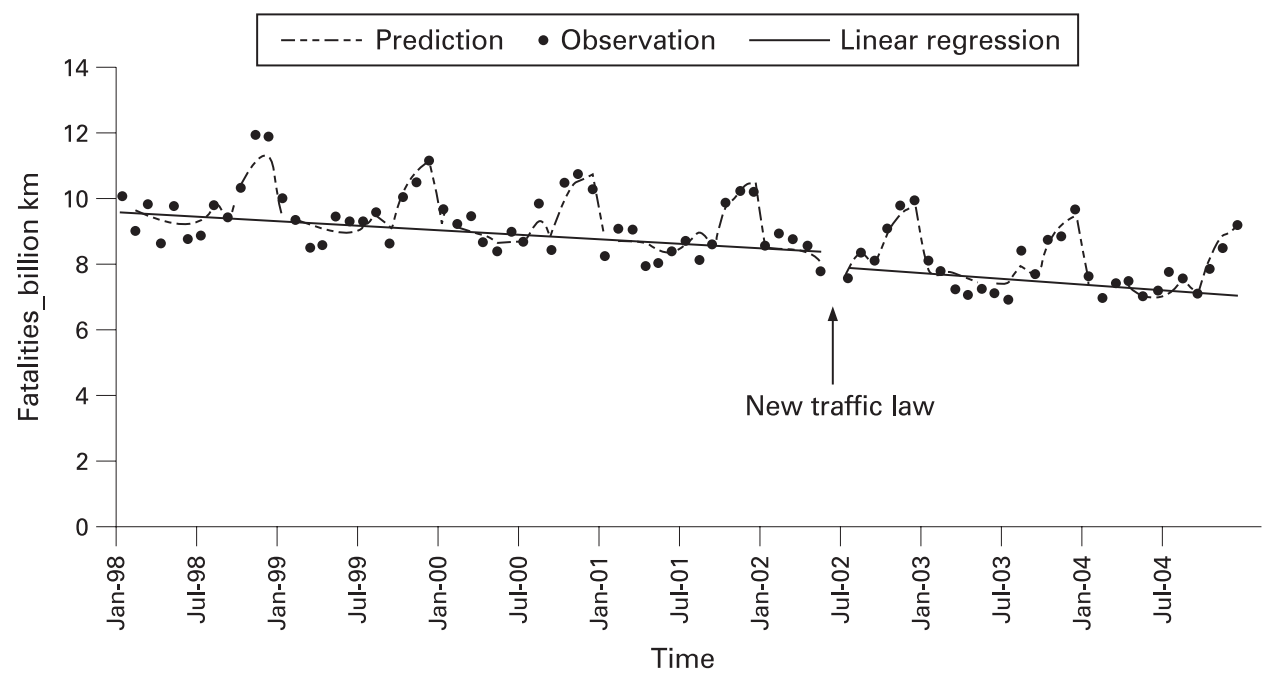

the introduction of the $0.08 \%$ BAC Law is controversial, but appears to have reduced AID; however, its effectiveness in reducing traffic injuries and fatalities has been debated. ${ }^{14}{ }^{15} \mathrm{An}$ earlier 1970 law in Japan setting the legal BAC at 0.05\% appeared to reduce traffic fatalities; however, it was not statistically evaluated..$^{18} 19$

Japan publicized the new law in a variety of ways, including mass media campaigns encouraging public transportation when drinking instead of driving. Not only the NPA but all the governmental agencies actively worked to announce the introduction of the road traffic law for AID. They also conducted a media campaign. The official advertisement for this campaign is memorable. In it, a drunken man tries to go home in his car. The bartender requests that he pay $\$ 4250$ (equal to the drinking driving penalty in Japan), which is more than the average monthly salary of most workers. This advertisement gave viewers a strong impression of how severe the penalty would be.

In this study, we find that the reduction in AID traffic injuries and fatalities in Japan, 2002, was a successful public health intervention, and believe the lessons learned from this policy change will be useful for other countries trying to cope with AID problems.

Figure 4 Observed and predicted all traffic injuries (per billion kilometers driven) using a stepwise autoregression model, Japan, 1998-2004.
We measured the effect of the new road traffic law on the decrease in victims of traffic crashes in a time series analysis. Time series analysis refers to a large series of observations made on the same variables repeatedly over time, and it is widely used in economic, physical, demographic, and public health studies to evaluate and predict the trend of a single characteristic in different time intervals. ${ }^{20} 21$

Some weaknesses of simple pre-post comparison studies are that long-term trends, slow or delayed effects, regression to the mean, and the correlated data are not properly considered. Time series analysis can overcome these weaknesses, and characterize the change in trend associated with the intervention more clearly.

The new road traffic law was associated with significant reductions in the baseline for all traffic injuries, all severe traffic injuries, AID traffic injuries, AID severe traffic injuries, and AID traffic fatalities per billion kilometers driven, and the total reduction in all traffic fatalities was borderline significant $(p=0.06)$. Only 15\% of traffic fatalities in Japan were alcoholrelated before the law, which has had its main impact on alcohol-related driving. ${ }^{42}$ After the law, alcohol-related fatalities fell to $11 \%$ (table 2). The primary effect of the new traffic law was to change the behavior of people who intended to drive

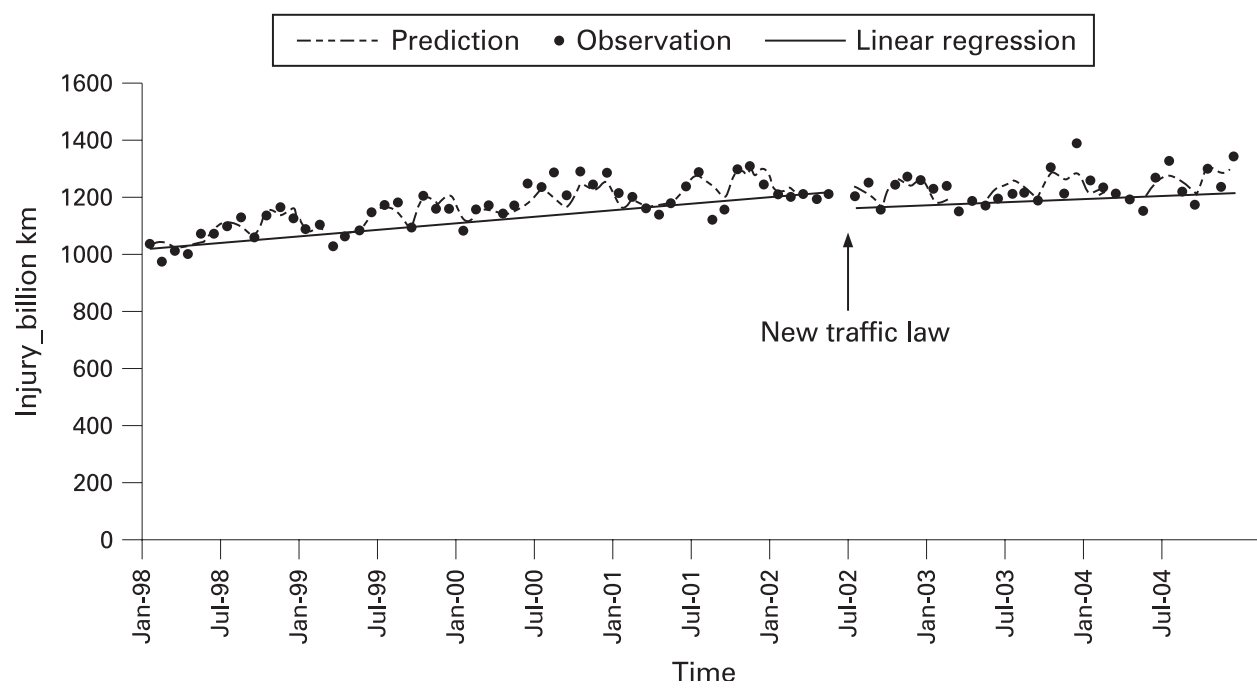




\section{Key points}

- Each year, more than 7000 people die as the result of road traffic injuries in Japan.

- In June 2002, the Japanese government enacted a new road traffic law to reduce AID.

- By applying time series analysis, we determined that baseline rates of all traffic injuries, severe traffic injuries, AID traffic injuries, AID severe traffic injuries, and AID traffic fatalities per billion kilometers driven declined significantly after the new traffic law.

- The Japanese policy appears to have been a successful public health measure.

a motor vehicle after drinking, which affected AID injuries but not the overall traffic fatality rate.

This study has various limitations. Firstly, the lowering of the definition of AID may have increased the number of alcoholrelated traffic crashes after the law, which may have caused bias in the estimation of alcohol-related traffic events over time. For example, before the new law, drivers with a BAC of $0.04 \%$ would not have been counted as AID, whereas after the new traffic law was implemented, they would be. Unfortunately, the numeric results of breath or blood alcohol testing were not available, nor was there information on the extent of missing data on breath or blood alcohol tests in classifying alcoholrelated motor vehicle events in Japan. Use of a consistent definition of AID throughout the period of observation was not possible because of changes in the law. However, the fact that significant reductions in AID events were seen after the law was enacted, even though the definition became more inclusive, suggests that AID reductions were considerable, and perhaps even larger than our estimates.

Secondly, data were not available on the proportion of drivers in non-fatal, serious injury, and fatal crashes who were tested for alcohol. In addition, the NPA does not have a standard protocol stipulating the acceptable time lag between collision and breath testing, and therefore it is unknown.

Thirdly, it was not possible to systematically control for external confounders such as other new traffic laws, campaigns, and overall alcohol consumption. However, to our knowledge no other major changes occurred between 1998 and 2003 that may have had a significant effect on traffic injuries. The commitment of law enforcement in the pre- and post-law period appears to be the same. A study showed that 140460 people were arrested for traffic violation between January and June 2002 (pre-law), and 133937 were arrested between January and June 2003 (post-law). ${ }^{47}$ The difference was not statistically significant.

Fourthly, it was not possible to stratify the data according to age groups, and therefore information about high-risk groups for traffic crashes, including alcohol-related ones, was not available from the public domain datasets used in this study. More detailed data will be necessary to examine the impact of the law on different age groups.

Our study finds that implementation of the new Japanese road traffic law was followed by a substantial decline in fatal and non-fatal motor vehicle injuries associated with AID. The Japanese policy appears to have been a very successful public health measure.

\section{CONCLUSION}

Despite some limitations, this study, by applying time series analysis, shows that the new Japanese road traffic law implemented in June 2002 had an effect on declining traffic injuries and fatalities. This success was obtained in several ways: decreasing the permissible blood alcohol level, increasing penalties, and an active media campaign. By describing the success of the AID intervention in Japan, the findings of this study may be helpful for other countries coping with the problems of AID

\section{IMPLICATIONS FOR PREVENTION}

National policies can have a significant effect in reducing AID by using multidisciplinary approaches that include enforcement and educational campaigns targeting driver behavior.

Acknowledgements: We thank Dr Yeong-Su Ju, Takemi Program in International Health, Harvard School of Public Health, for supporting the data analysis, and Danielle Stockley, Department of Environmental Health, Harvard School of Public Health, for assistance with editing the manuscript.

Funding: MP received partial support for this work in the form of grant $\mathrm{No} 442 \mathrm{OH}$ 008416-02, from the US National Institute for Occupational Safety and Health (NIOSH).

Competing interests: None.

\section{REFERENCES}

1. National Highway Traffic Safety Administration. State laws and practices for BAC testing and reporting drivers involved in fatal crashes. Washington, DC: US Department of Transportation, 2004. Report DOT HS 809756.

2. World Health Organization. World report on road traffic injury prevention. Geneva: WHO, 2004.

3. Mann RE, Macdonald S, Stoduto LG, et al. The effects of introducing or lowering legal per se blood alcohol limits for driving: an international review. Accid Anal Prev 2001;33:569-83.

4. National Police Agency. Police report about fatal traffic crashes in 2003. Tokyo: NPA, 2004 (in Japanese).

5. Shimizu S. Tougher penalties for drink driving in Japan. Addiction 2001;96:1866,

6. Nakahara S, Wakai S. Underreporting of traffic injuries involving children in Japan. Inj Prev 2001;7:212-14.

7. Institute for Traffic Accident Research and Data Analysis, Japan. http:// www.itarda.or.jp/english/eg_home.html (accessed 12 Dec 2007).

8. Ministry of Land Infrastructure and Transport, Japan. http://toukei.mlit.go.jp/ jidousya/iidousya.html (accessed 12 Dec 2007).

9. Gillings D, Makuc D, Siegel E. Analysis of interrupted time series mortality trends: an example to evaluate regionalized perinatal care. Am J Public Health 1981;71:38-46.

10. Kennedy P. Autocorrelated disturbances. In: A guide to econometrics. 4th edn. Cambridge, MA: MIT Press, 1998:123-5.

11. University of California. SAS/ETS user's guide. The AUTOREG procedure.http:// www.uc.edu/sashtml/ets/chap8/index.htm (accessed 12 Dec 2008).

12. Hitosugi M, Sorimachi $Y$, Kurosawa A, et al. Risk of death due to alcohol-impaired driving in Japan. Lancet 2003;361:1132.

13. Imai $\mathbf{H}$. The new traffic law and reduction of alcohol related fatal crashes in Japan Inj Prev 2003;9:382.

14. Tippetts AS, Voas RB, Fell JC. A meta-analysis of .08 BAC laws in 19 jurisdictions in the United States. Accid Anal Prev 2005;37:149-61.

15. Hingson R, Heeren T, Winter M. Lowering state legal blood alcohol limits to $0.08 \%$ the effects on fatal motor vehicle crashes. Am J Public Health 1996;86:1297-9.

16. Foss RD, Stewart JR, Reinfurt DD. Evaluation of the effects of North Carolina's 0.08\% BAC law. Accid Anal Prev 2001;33:507-17.

17. Wagenaar AC, Zobeck TS, William GD, et al. Methods used in studies of drink-drive control efforts: a meta-analysis of the literature from 1960 to 1991. Accid Anal Prev 1995;2:307-16

18. Deshapriya EB, Iwase N. Impact of the 1970 legal BAC $0.05 \mathrm{mg} \%$ limit legislation on drunk-driver-involved traffic fatalities, accidents, and DWI in Japan. Subst Use Misuse 1998;33:2757-88.

19. Deshapriya EB, Iwase N. Are lower legal blood alcohol limits and a combination of sanctions desirable in reducing drunken driver-involved traffic fatalities and traffic accidents? Accid Anal Prev 1996;28:721-31

20. Shadish WR, Cook TD, Campbell DT. Experimental and quasi-experimental design for generalized causal inference. US: Houghton Mifflin, 2002.

21. Wanger AK, Soumerai SB, Zhang F. Segmented regression analysis of interrupted time series studies in medication use research. J Clin Pharm Ther 2002;27:299-309. 


\section{CALENDAR}

\section{Children and Injuries}

31 August-3 September 2008, Cape Town, South Africa. Child Accident Prevention Foundation of Southern Africa will host the founding conference of the International Society for Violence and Injury Prevention. The aim of this conference is to consider issues associated with alcohol, children and injuries. Further information: http://tinyurl. com/2f8h9s.

\section{International Electrical Product Safety Conference 2008}

8-9 September 2008, London, UK. The International Electrical Product Safety Conference 2008 aims to address the current big issues in consumer product safety. The conference, being organized by the Electrical Safety Council, will embrace the economic, legislative, and global aspects of consumer product safety by tackling the safety of imported goods, the revision of the New Approach and the Low Voltage Directive, on-going initiatives in market surveillance, and counterfeiting. Further information: http://www.escconference. org.uk/.

\section{2nd European Conference on Injury Prevention And Safety Promotion}

9-10 October, 2008, Paris, France. The conference is being organized by EuroSafe in collaboration with the French Consumer Safety Commission (Commission de la Sécurité des Consommateurs). The main objective of the conference is to help move forward the implementation of the EU Council Recommendation adopted in May 2007. The Recommendation invites Member States to make better use of existing injury data and develop national injury surveillance and reporting systems; and set up national plans for injury prevention that include safety promotion in education and professional training. Further information and online abstract form: http://tinyurl. com $/ 552 x 7 y$. 17th International Safe Communities Conference

20-23 October 2008, Christchurch, New Zealand. The main theme of the conference is Working together to make a difference. Further information: http:// www.safecom2008.org.nz/.

2nd Asia Pacific Injury Prevention Conference. 40th APACPH Annual Conference

4-6 November 2008, Hanoi, Vietnam. The integration of the APACPH conference and the Asia-Pacific Injury Prevention Conference will create an environment for the discussion of public health issues in the region. The meeting is also an opportunity for national and international organizations working in the field of public health to share in-depth information on the current status of injuries and accidents in the regional and beyond. Further information: http://www. apacph2008.org.

First Regional Conference on Injury Prevention and Promotion. Development and Safety-Together

10-12 February 2009, Cairo, Egypt. There is a pressing need to increase the awareness of preventing and controlling injuries in the Eastern Mediterranean region. Without such a conference to focus attention on the significant morbidity and mortality caused by trauma, it may be many years before adequate attention is given to the magnitude of the injury problem in this important region. Abstracts can be submitted between 15 May and 15 August 2008. Further information: http://www. emro.who.int/vip/ipsp/.

18th International Conference on Safe Communities Community Safety Policies as an Axis for Development

13-15 August 2009, Cali, Colombia. For information: http://www.cisalva.univalle. edu.co/EN/index.html.

19th International Safe Communities Conference: Sustainability of Safe Community Programs

23-26 March 2010, Suwon, Korea. For information: contact jpcho@ajou.ac.kr.

\section{CORRECTION}

doi:10.1136/ip.2007.015719.corr1

Nagata T, Setoguchi S, Hemenway D, Perry MJ. Effectiveness of a law to reduce alcoholimpaired driving in Japan. Inj Prev 2008;14:19-23.

This article includes duplication of text from sections of a previous manuscript by three of the same authors published in the Japan Medical Association Journal. ${ }^{1}$

The paper published in Injury Prevention was submitted in July 2005. During the process of peer review and revision, an early draft was also submitted to the JMAJ and published there in December 2006. That paper used a before and after design to assess the impact of changes to an alcoholimpaired driving law. The version ultimately published in Injury Prevention looked at the effect of the same law but included a longer period of observation and a more sophisticated time series analysis.

Dr Setoguchi was only involved with the time series analyses published in Injury Prevention and was not involved with the manuscript published in JMAJ.

Because of these substantial differences, the editors believe that this does not represent duplicate publication of data. However, portions of text from the background and discussion section of the JMAJ publication are also found in the Injury Prevention paper. In addition, the submission to Injury Prevention does not cite or acknowledge the JMAJ manuscript.

A corrected pdf version of the Injury Prevention paper is published online (linked to the original version http://injuryprevention.bmj.com/ content/vol14/issue1). The authors apologise to the readers of Injury Prevention for this oversight and for any confusion it might create.

T Nagata, S Setoguchi, D Hemenway, M J Perry

\section{REFERENCE}

1. Nagata T, Hemenway D, Perry MJ. The effectiveness of a new law to reduce alcohol impaired driving in Japan. Japan Medical Association Journal 2006;49:365-9. 